Correction

\title{
Correction: Fry et al. Global Leadership for Sustainability. Sustainability 2021, 13, 6360
}

\author{
Louis W. Fry ${ }^{1, *}$ and Eleftheria Egel ${ }^{2, *}$ (1) \\ 1 Department of Management, Texas A\&M University-Central Texas, 1001 Leadership Place, \\ Killeen, TX 76549, USA \\ 2 Navigating Transformation, Female Entrepreneurship Consultancy, 79379 Muellheim, Germany \\ * Correspondence: lwfry@tamuct.edu (L.W.F.); NavigatingTransformation@amfortas.eu (E.E.)
}

check for

updates

Citation: Fry, L.W.; Egel, E. Correction: Fry et al. Global Leadership for Sustainability. Sustainability 2021, 13, 6360. Sustainability 2021, 13, 12209. https://doi.org/10.3390/su 132112209

Received: 13 October 2021 Accepted: 26 October 2021 Published: 5 November 2021

Publisher's Note: MDPI stays neutral with regard to jurisdictional claims in published maps and institutional affiliations.

Copyright: (c) 2021 by the authors. Licensee MDPI, Basel, Switzerland. This article is an open access article distributed under the terms and conditions of the Creative Commons Attribution (CC BY) license (https:// creativecommons.org/licenses/by/ $4.0 /)$.
The authors would like to make the following corrections to the published paper [1] The changes are as follows:

(1) Replacing the sentence in "Section 6.2.2. Leadership for Sustainability Through Hope/Faith, Vision, and Altruistic Love" on page 19: Replacing the original version:

- administer GLfS Survey to establish a baseline and raise key issues [158]; with

- administer GLfS Survey to establish a baseline and raise key issues (See Appendix A) [158];

(2) Adding Appendix A after the part "Conflicts of Interest"

\section{Appendix A}

Global Leadership for Sustainability Survey

I. Global Mindset for Sustainability-the extent to which one seeks mindful awareness or presence in the now (Level of Being III). *

1. _ (Q6) I do jobs or tasks automatically, without being aware of what I'm doing.

2. _ (Q18) I find it difficult to stay focused on what's happening in the present.

3. (Q30) I could be experiencing some emotion and not be conscious of it until sometime later.

4. _ (Q42) I find myself doing things without paying attention.

5. (Q50) I forget a person's name almost as soon as I've been told it for the first time.

* These items are reverse scored $(5=1,4=2,3=3,2=4,5=1)$.

Total Score $/ 5=$

\section{Leadership for Sustainability}

Vision-describes the organization's journey and why we are taking it; defines who we are and what we do.

1. (Q1) My company has a vision for a sustainable world that brings out the best in me.

(Q13) My organization's vision for sustainability inspires my best performance. (Q25) My organization has a vision for sustainability that I am committed to. (Q37) My organization's vision for sustainability is clear and compelling to me.

Total Score $/ 4=$

Hope/Faith-the assurance of things hoped for, the conviction that the organization's vision/purpose/mission will be fulfilled. 
1. (Q2) I have faith in my organization and I am willing to "do whatever it takes" to ensure that it accomplishes its vision for sustainability.

2. _ (Q14) I demonstrate my faith in my organization and its vision for sustainability by doing everything I can to help us succeed.

3. (Q26) I persevere and exert extra effort to help my organization succeed because I have faith in its commitment to sustainability.

4. (Q38) I set challenging goals for my work because I have faith in my organization's vision for sustainability and want us to succeed.

Total Score $/ 4=$

Altruistic Love-a sense of wholeness, harmony, and well-being produced through care, concern, and appreciation for both self and others.

1. (Q3) The leaders in my organization" walk the walk" as well as "talk the talk".

2. _ (Q15) The leaders in my organization are honest and without false pride.

3. _ (Q27) My organization is trustworthy and loyal to its employees.

4. _ (Q39) The leaders in my organization have the courage to stand up for their people.

5. _ (Q49) My organization is kind and considerate toward its workers, and when they are suffering, want to do something about it.

Total Score $/ 5=$

\section{Spiritual Well-Being}

Meaning/Calling - a sense that one's life has purpose, meaning, and makes a difference.

1.

2.

3.

4.

Total Score
(Q4) The work I do related to sustainability makes a difference in people's lives. (Q16) The work I do is meaningful to me. (Q28) The work I do is very important to me. (Q40) My job activities related to sustainability are personally meaningful to me.

Membership - a sense that one is understood and appreciated.

1. _ (Q5) I feel my organization appreciates me and my work for sustainability.

2. __ (Q17) I feel my organization demonstrates respect for me and my passion for sustainability.

3. __ (Q29) I feel I am valued as a person in my job.

4. _ _ (Q41) I feel highly regarded by my leaders.

Total Score $/ 4=$

\section{Triple Bottom Line}

Economic

Organizational Commitment-the degree of loyalty or attachment to the organization.

1. _ (Q7) I really feel as if my organization's problems are my own.

2. (Q19) I would be very happy to spend the rest of my career with this organization.

3. _ (Q31) I talk up this organization to my friends as a great place to work.

4. _ (Q43) I feel a strong sense of belonging to my organization.

Total Score $/ 4=$

Productivity-Work group efficiency in producing results, benefits, or profits.

1. _ (Q8) In my department, everyone gives his/her best efforts.

2. _ _ (Q20) In my department, work quality is a high priority for all workers.

3. _ (Q32) My work group is very productive.

4. _ (Q44) My work group is very efficient in getting maximum, output from the resources (money, people, equipment, etc.) we have available.

Total Score $/ 4=$

Organizational Economic Factors 
1. _ (Q11) My organization is recognized for the service given to its customers.

2. _ (Q23) My organization is recognized for the quality of its products/services.

3. _ (Q35) My company is recognized as being financially successful.

4. _ (Q47) My organization actively controls the costs of operating (e.g., supply chain, recycling).

5. _ (Q52) My company closely monitors employee productivity and efficiency.

Total Score $/ 5=$

\section{Social}

Satisfaction with Life-one's sense of subjective well-being or satisfaction with life as a whole.

1 . (Q9) I am satisfied with my life.

2. _ (Q21) In most ways my life is ideal.

3. _ (Q33) If I could live my life over, I would change almost nothing.

4. _ (Q45) So far, I have gotten the important things I want in life.

Total Score $/ 4=$

\section{Social and Stakeholder Responsibility}

1. (Q10) My organization believes that it has an obligation to serve the community in which it operates.

2. (Q22) My organization is committed to being socially responsible.

3. (Q34) My organization considers the consequences of its decisions on affected stakeholders.

4. _ (Q46) My organization weighs different stakeholder interests before making a decision.

5. (Q51) My organization demonstrates awareness of the claims of social and environmental stakeholders.

Total Score $/ 5=$

\section{Environmental}

1. (Q12) My organization seeks to assess the impact our operations on the environment.

2. __ (Q24) My company is recognized for working to minimizing its environmental impact.

3. (Q36) My organization has adopted specific initiatives to reduce its environmental impact.

4. __ (Q48) My company has a program in place to reduce the amount of energy and materials wasted in our business.

5. _ (Q53) My organization's leaders are committed to environmental sustainability.

Total Score $/ 5=$

The authors and the Editorial Office would like to apologize for any inconvenience caused to the readers and state that the scientific conclusions are unaffected. The original article has been updated.

\section{Reference}

1. Fry, L.W.; Egel, E. Global Leadership for Sustainability. Sustainability 2021, 13, 6360. [CrossRef] 